\title{
CARPO-METACARPAL DISLOCATION
}

\section{Report of Four Cases}

\section{Edmund Shephard, Maidstone, and D. J. Solomon, Tunbridge Wells, England}

Carpo-metacarpal dislocation other than of the thumb alone is uncommon. Waugh and Yancey (1948) collected eighty-three published cases, and added two of their own. Picchio (1954) listed 100 instances.

Complete carpo-metacarpal dislocation - that is, of all five metacarpals of one hand-is rare. Waugh and Yancey (1948) drew attention to five recorded cases, those of Rivington (1873), Poulet (1884), McLean (1922), Michaelsshon cited by Mittler (1937), and Triksen cited by Binotto (1940).

Aulong and Girard (1951) reported a further case of complete carpo-metacarpal dislocation with fracture of the base of the fifth metacarpal bone. They were unwilling to accept Poulet's and Triksen's cases because the evidence was based only on plaster casts. Picchio (1954) reported no additional case of complete carpo-metacarpal dislocation. In Trojan's (1952) patient the second to fifth metacarpals were dislocated dorsally, but the trapezium was displaced with the first metacarpal, the first carpo-metacarpal joint not being disturbed.

Waugh and Yancey recorded thirty-one cases of dislocation of the four medial carpometacarpal joints together, and eleven cases, including two of their own, of combined dislocation of the fourth and fifth metacarpal bases.

Four cases are here presented: one of dislocation of all five carpo-metacarpal joints of one hand; one of dislocation of the four medial carpo-metacarpal joints with subluxation of the corresponding thumb joint; one of dislocation of the four medial carpo-metacarpal joints; and one of dislocation of the fourth and fifth carpo-metacarpal joints.

\section{CASE REPORTS}

Case 1-A woman of fifty-six was struck by a car, sustaining severe multiple injuries to trunk and limbs. The left hand showed dorsal dislocation of all five metacarpals on the carpus (Fig. 1), and a fracture of the second metacarpal neck, over the dorsum of which was a small laceration. At operation undertaken for major injuries, reduction of the left carpo-metacarpal dislocation was attempted without success. A further attempt, just before the patient left the theatre, succeeded at once (Fig. 2), perhaps because the prominent second metacarpal base happened to enter its mortise. The patient died twenty-four hours after the accident.

Necropsy findings-Examination of the left hand at necropsy showed that the dorsal capsule of the carpo-metacarpal joints was intact except for a small longitudinal split. Dislocation was easily reproduced by forward pressure applied to the metacarpal heads. Then the metacarpal bases overlapped the carpus by one inch. From the dorsum of the carpus, and from the front of the metacarpal bases the soft tissues were found stripped for one inch. After redislocation, reduction was impossible even by leverage, until the extensor tendons were divided, when it became easy.

Case 2-A man of twenty-four, a tree feller, rode his motor cycle head-on into the side of a shooting brake. On his admission to the Kent and Sussex Hospital there was a large haematoma on the dorsum of the left hand and distal half of the forearm. Radiographs (Fig. 3) showed dorsal dislocation of the four medial metacarpal bases, and subluxation of the first metacarpal base. In addition, the hamate, capitate, trapezium, scaphoid tuberosity and fifth metacarpal base showed fracture. 


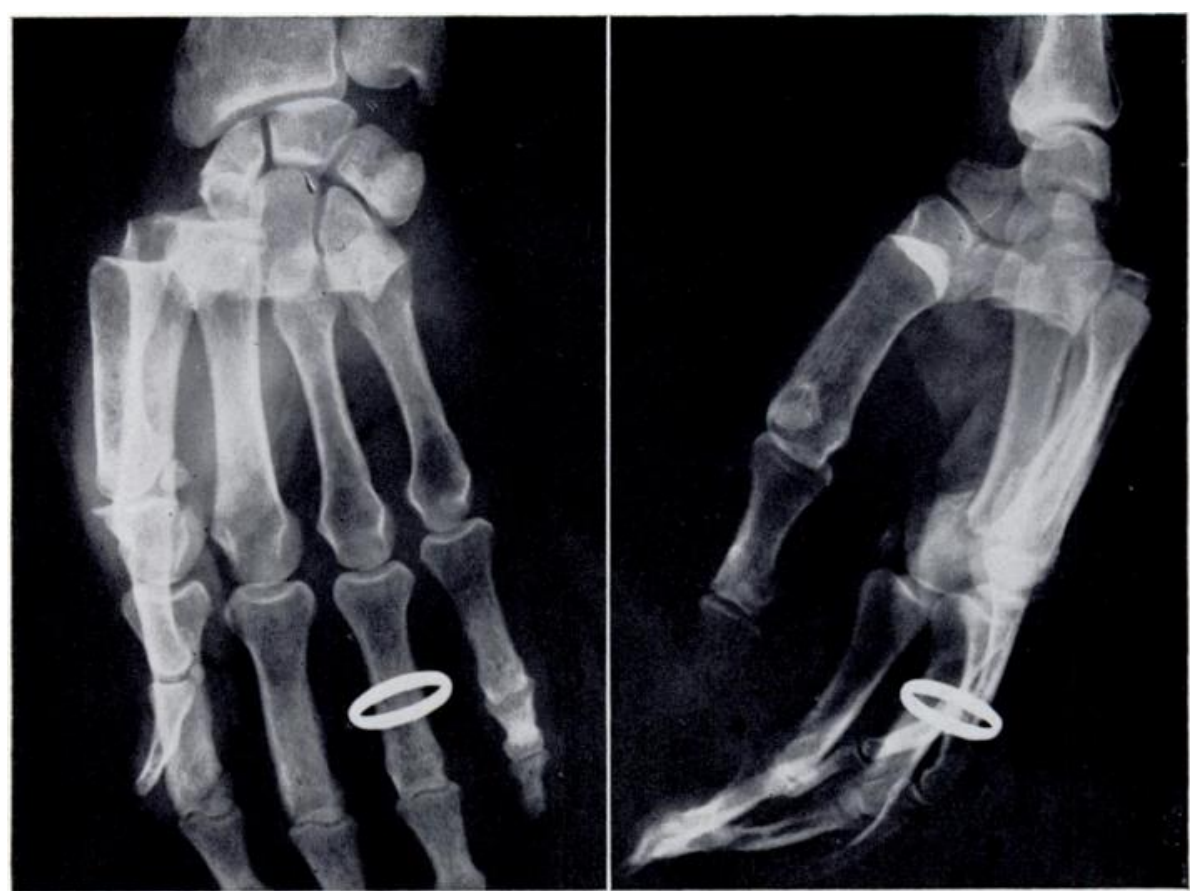

FIG. 1

Case 1-Left hand. Dorsal dislocation of all five carpo-metacarpal joints, and fracture of second metacarpal neck.

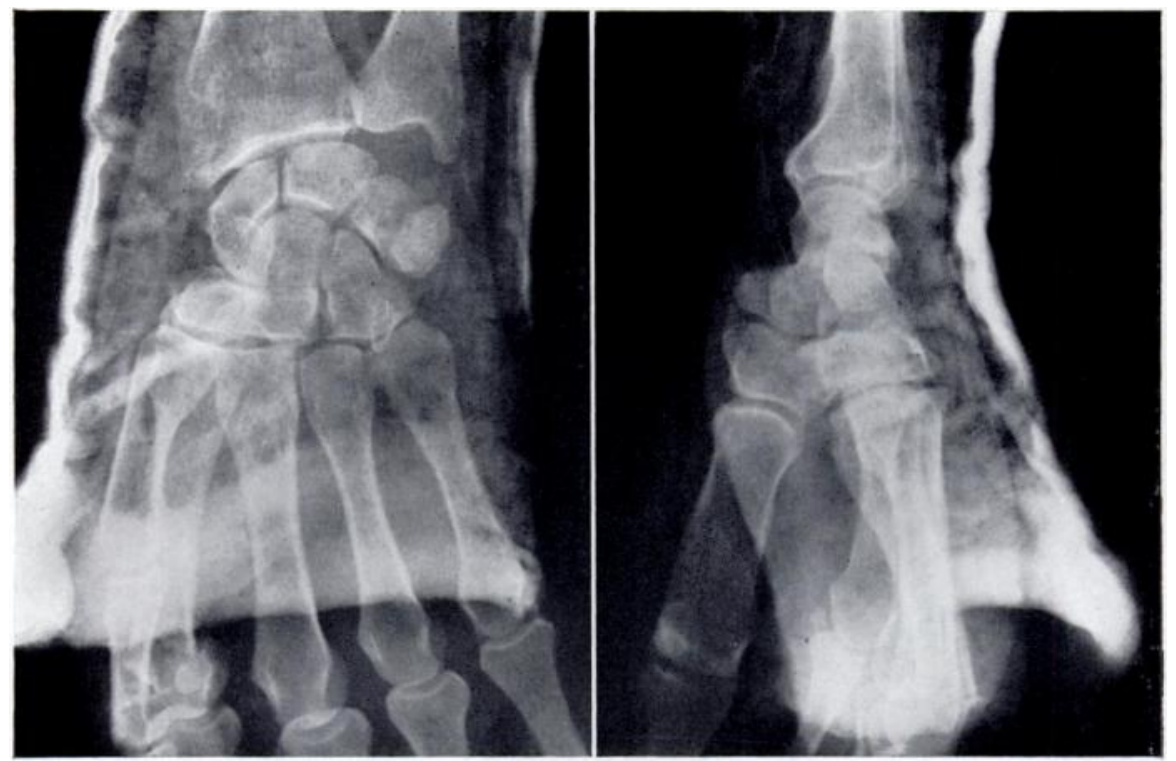

Fig. 2

Case 1-Radiograph after reduction.

To facilitate manipulative reduction under anaesthesia, blood and clots amounting to seven ounces ( 200 millilitres) were evacuated through a short incision on the dorsum of the hand. Reduction was then obtained easily by traction on the thumb and four fingers, both thumbs of the operator applying pressure on the metacarpal bases. The wound was drained and an anterior plaster splint applied with the wrist extended.

VOL. 42 B, NO. 4, NOVemBer 1960 


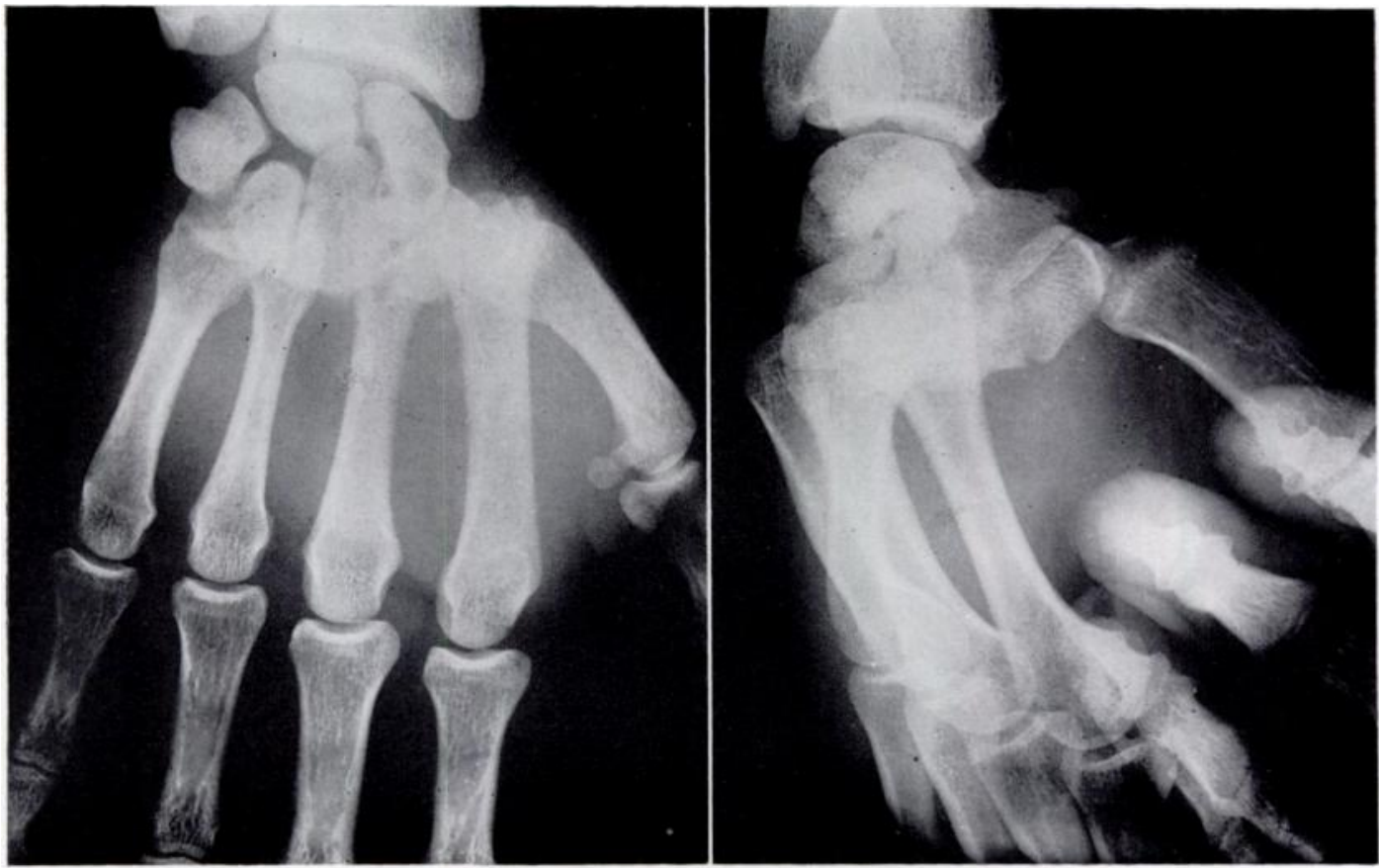

FIG. 3

Case 2-Left hand. Dorsal dislocation of the four medial carpo-metacarpal joints and subluxation of the corresponding thumb joint with fractures of hamate, capitate, trapezium, scaphoid tuberosity and fifth metacarpal base.
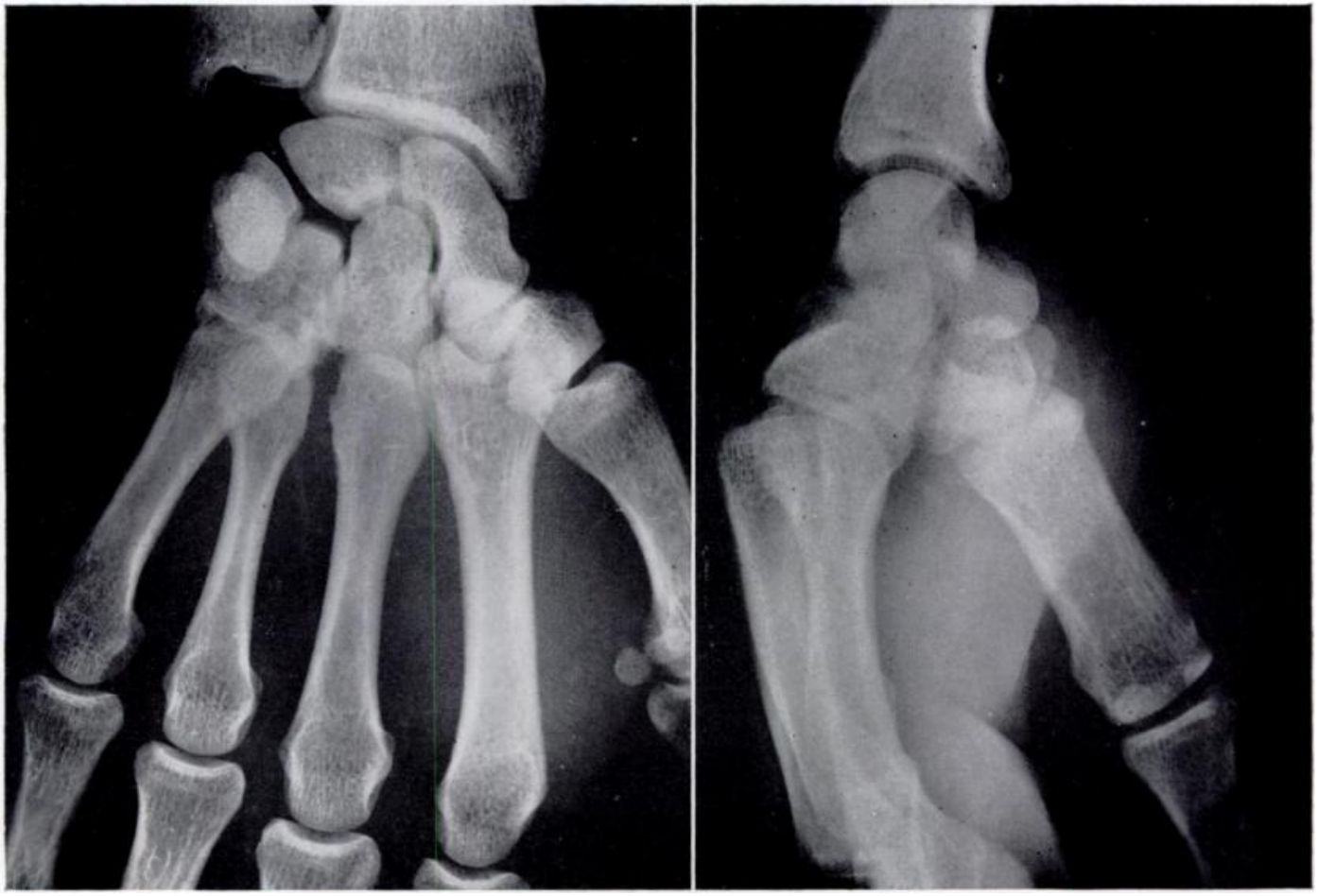

FiG. 4

Case 2-Radiograph after reduction.

THE JOURNAL OF BONE AND JOINT SURGERY 


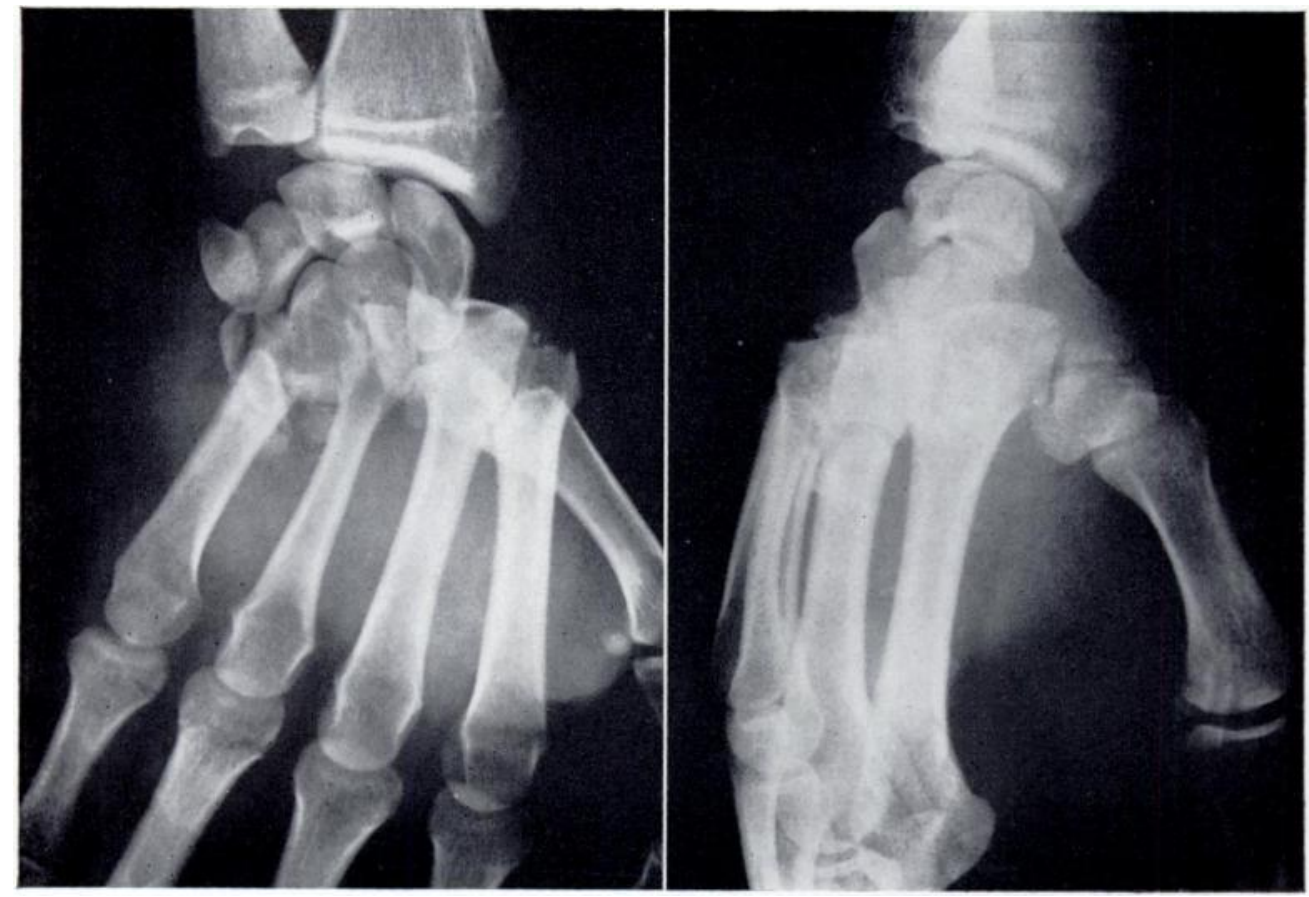

FIG. 5

Case 3-Right hand. Dorsal dislocation of the four medial carpo-metacarpal joints.

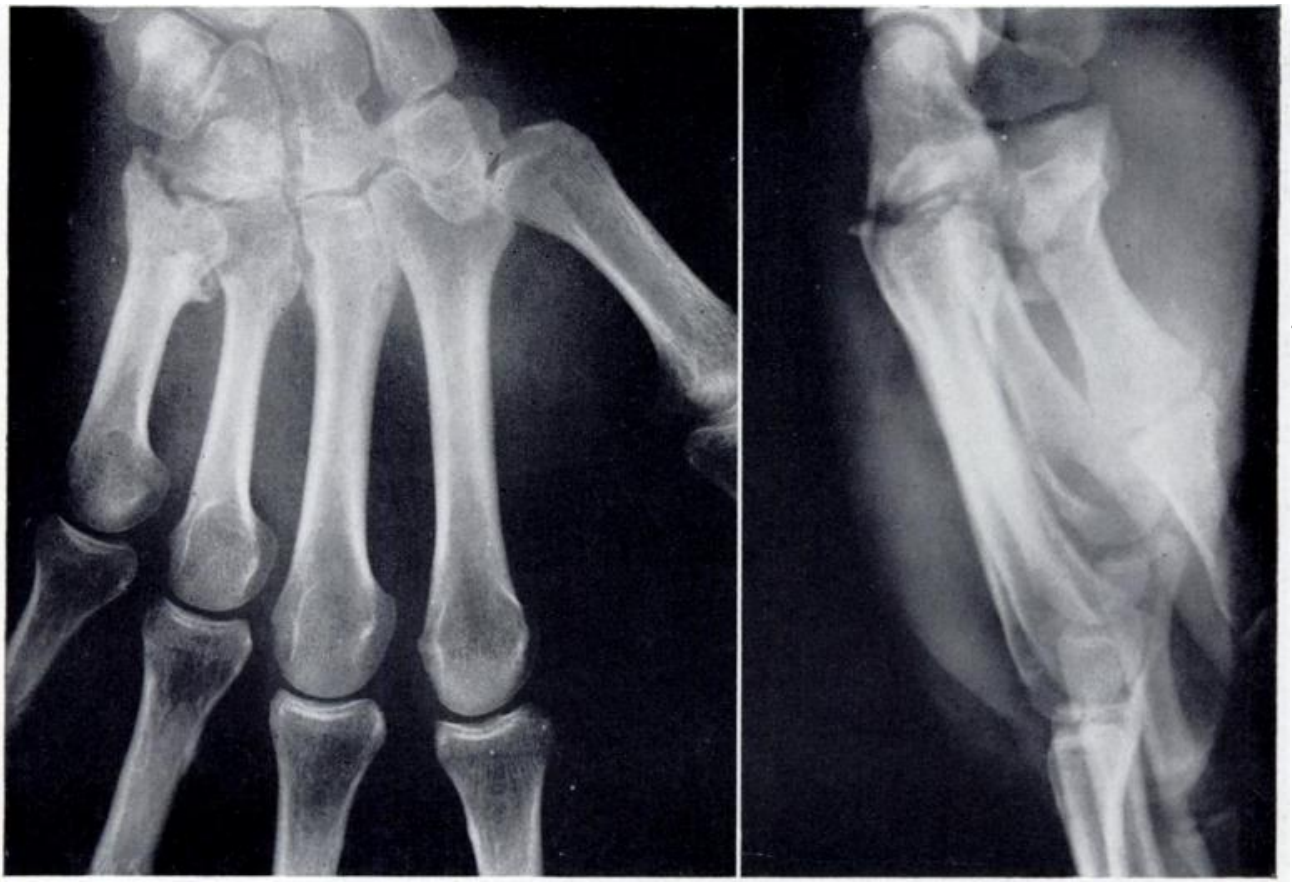

Fig. 6

Case 3-Radiograph after reduction. 


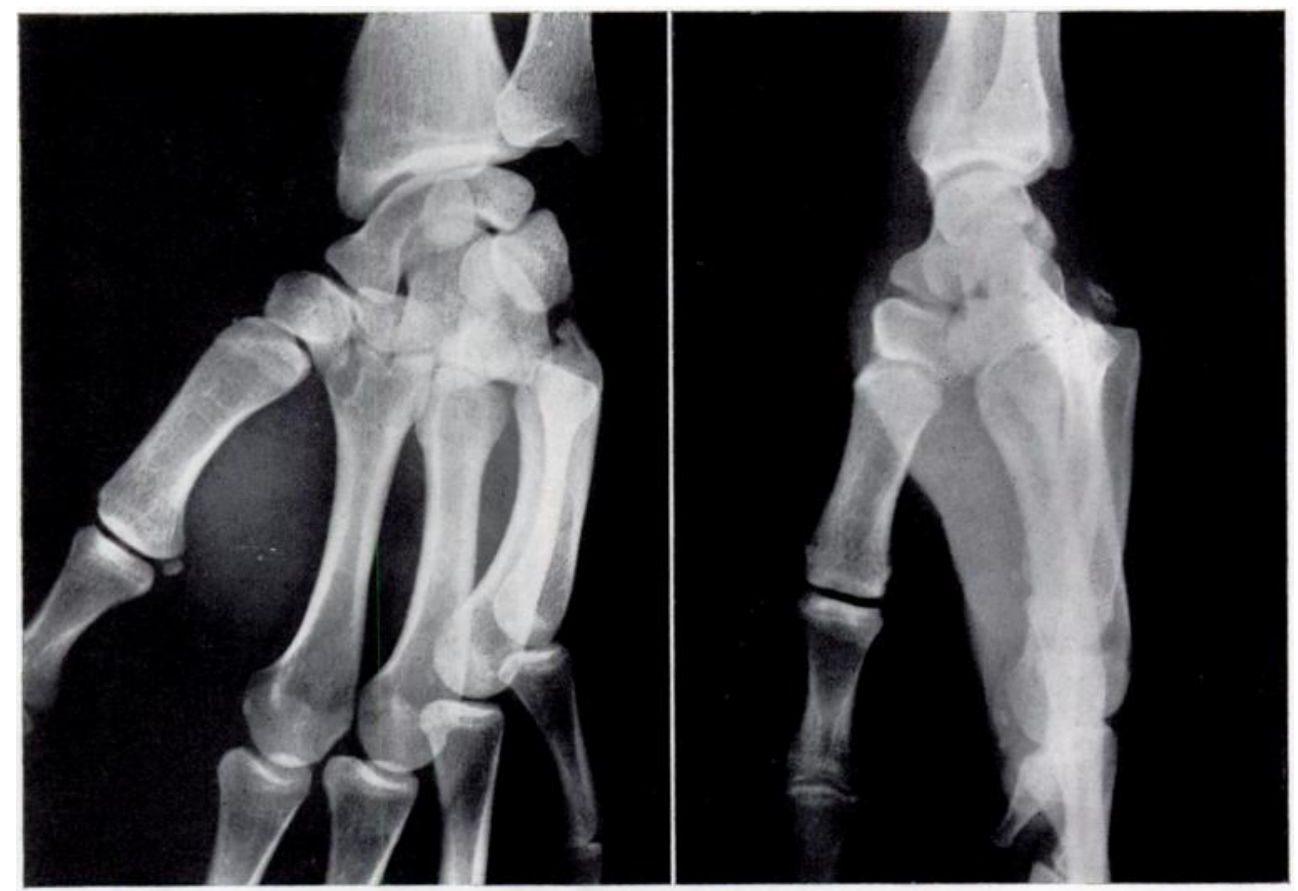

FIG. 7

Case 4-Left hand. Dorsal dislocation of fourth and fifth carpo-metacarpal joints, with flake fracture of hamate bone.

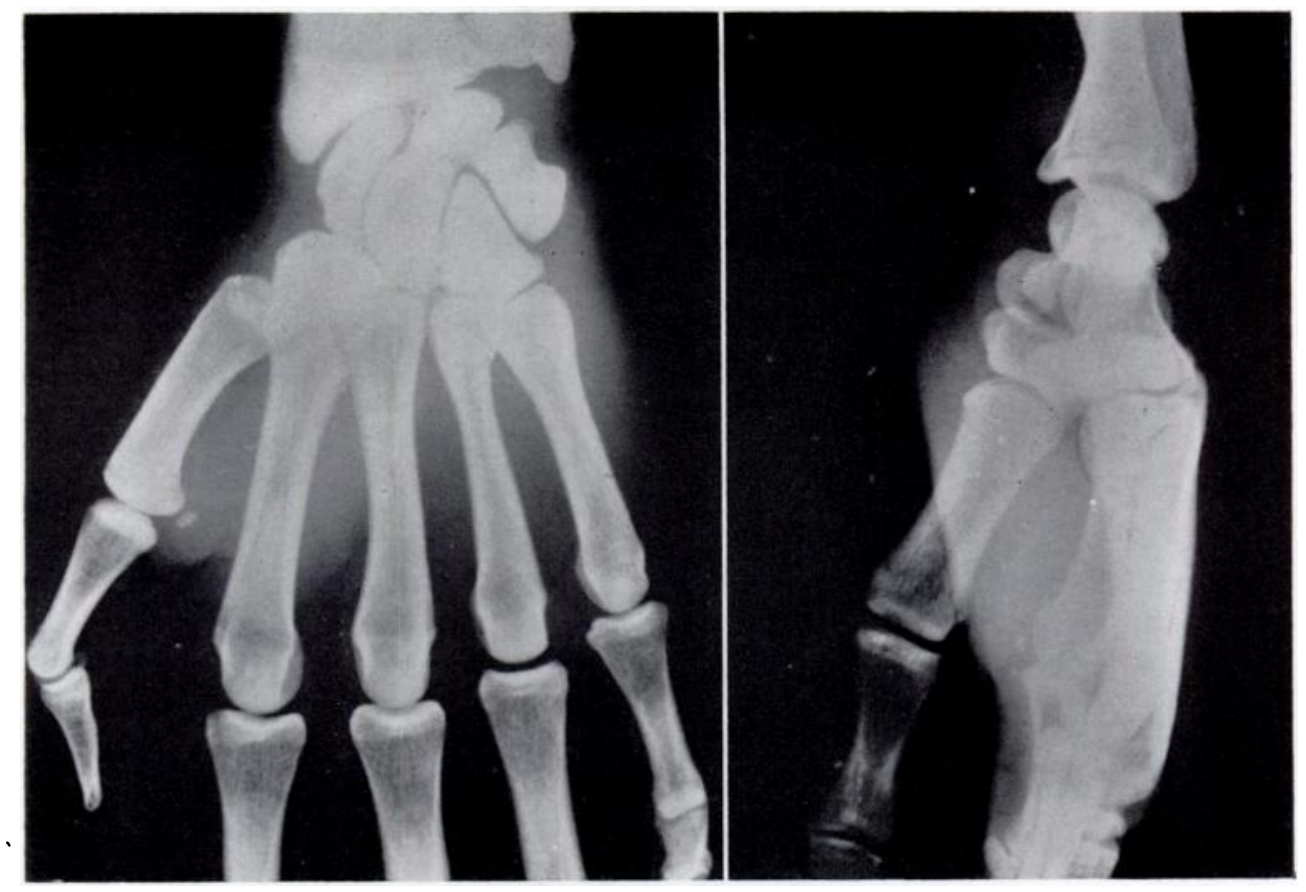

FIG. 8

Case 4-Radiograph after reduction. 
Radiographs (Fig. 4) showed reduction, with slight persistent dorsal displacement of the fourth and fifth metacarpal bases, associated with comminution of the hamate.

The drain was removed after forty-eight hours; thereafter a plaster case was applied and maintained for six weeks. Three months after the injury function was excellent and the grip strong. The fourth and fifth metacarpal bases were slightly prominent on the dorsum of the hand. The patient is now working as a self-employed contractor.

Case 3-A man of eighteen, a fitter-turner apprentice, was admitted to the West Kent General Hospital after a motor-cycle accident with fractures of the right thigh and leg, and dorsal dislocation of the four right medial carpo-metacarpal joints (Fig. 5). At the initial operation the hand injury was disregarded, but two days later the carpo-metacarpal dislocation was reduced easily under anaesthesia, and a plaster was applied and maintained for five weeks (Fig. 6). Full movement and function were regained, with slight prominence on the dorsum of the hand.

Return to work has been delayed by the lower limb injuries.

Case 4-A youth of seventeen, of no occupation, attended the Kent and Sussex Hospital with a painful left hand after a motor-cycle accident. He was unable to describe the mechanism of the injury. Radiographs confirmed the clinical diagnosis of dorsal dislocation of the fourth and fifth metacarpal bases, and showed a flake fracture of the hamate bone (Fig. 7). Reduction under anaesthesia was easily gained by traction and local pressure (Fig. 8). A plaster case was applied with the wrist extended, and maintained for six weeks. Function is normal. The patient has enrolled as an art student.

\section{COMMENT}

In Cases 2, 3 and 4 the patients were motor cyclists, and the dislocation might be attributed to impact of the handle bar on the metacarpal bases in the palm. Aulong and Girard (1951) so explained their complete dislocation. Pressure by a car steering wheel has also been held responsible.

In Case 1 another mechanism must be adduced. Perhaps the limb was flung outwards until checked by the dorsum of the metacarpal heads striking some object. If the muscles were tensed the momentum of the limb could have been transmitted to the metacarpal bases by abductor pollicis longus, extensores carpi radiales and extensor carpi ulnaris. The blow on the dorsum of the metacarpal heads together with the pull of these extensors may have caused the dislocation.

\section{SUMMARY}

Four cases of carpo-metacarpal dislocation are described. In one case all five metacarpals of one hand were involved.

We wish to thank Mr W. Harvey Gervis for permission to report Cases 2 and 4, and for encouragement in the preparation of this paper.

\section{REFERENCES}

Aulong, J., and GiRARD, J. (1951): Les luxations carpo-métacarpiennes. Revue de Chirurgie Orthopédique, $37,439$. BinotTo, A. (1940): Lussazione volare carpo-metacarpica completa. Minerva Medica, 31, 472.

McLean, E. H. (1922): Carpometacarpal Dislocation. Journal of the American Medical Association, 79, 299. MitTler, L. (1937): Sul meccanismo di produzione di una lussazione antero interna del IV e V metacarpo. Rivista di Chirurgia, 3, 487.

Picchio, A. (1954): Sulle lussazioni carpo-metacarpiche. Minerva Chirurgica, 9, 43.

Poulet (1884): Sub-luxation des cinq métacarpiens sur le carpe, réduction après un mois. Bulletins et Mémoires de la Société de Chirurgie de Paris, 10, 902.

Rivington (1873): Compound Dislocation of All the Metacarpal Bones of the Right Hand; Operation; Recovery with a Serviceable Hand. Lancet, i, 270.

Trojan, E. (1952): Ein Beitrag zu einer seltenen offenen divergierenden Carpo-Metacarpal- und Intercarpalverrenkung der rechten Hand. Monatsschrift für Unfallheilkunde, 55, 65.

WAUGH, R. L., and YANCEY, A. G. (1948): Carpometacarpal Dislocations. Journal of Bone and Joint Surgery, 30-A, 397.

VOl. 42 B, NO. 4, NOVEMBER 1960 